\title{
Effects and safety of neostigmine for postoperative recovery of gastrointestinal function: a systematic review and meta-analysis
}

\author{
Yan Liao, Yang Li, Wen Ouyang \\ Department of Anesthesiology, Third Xiangya Hospital, Central South University, Changsha, China \\ Contributions: (I) Conception and design: W Ouyang; (II) Administrative support: Y Liao; (III) Provision of study materials or patients: Y Li; (IV) \\ Collection and assembly of data: Y Li; (V) Data analysis and interpretation: Y Liao, W Ouyang; (VI) Manuscript writing: All authors; (VII) Final \\ approval of manuscript: All authors. \\ Correspondence to: Prof. Wen Ouyang. Department of Anesthesiology, Third Xiangya Hospital, 138 Tongzipo Road, Yuelu District, Changsha 410013, \\ China. Email: ouyangwen133@vip.sina.com.
}

\begin{abstract}
Background: The purpose of this study was to evaluate the clinical effects and safety of neostigmine for the postoperative recovery of gastrointestinal function.

Methods: We performed a literature search of multiple databases [PubMed, Web of Science, Cochrane Library and China National Knowledge Internet (CNKI)] to retrieve studies comparing the postoperative gastrointestinal function of neostigmine and control groups. Review Manager 5.2 was applied for the analysis of heterogeneity, sensitivity, and bias.

Results: After screening the articles, 17 trials involving 1,589 postoperative patients that met the eligibility criteria were included. The results suggested that neostigmine improved the first passage of flatus [standard mean difference $(\mathrm{SMD})=-3.00 ; 95 \%$ confidence interval $(\mathrm{CI}):(-4.03,-1.97) ; \mathrm{P}<0.001)$, first defecation [SMD $=-3.75 ; 95 \% \mathrm{CI}:(-5.25,-2.24) ; \mathrm{P}<0.001]$, time of bowel sound recovery [SMD $=-3.42 ; 95 \% \mathrm{CI}$ : (-4.49, -2.36), $\mathrm{P}<0.001$ ], and gastrointestinal function recovery [risk ratio (RR) $=1.84$; $95 \%$ CI: $(1.19,2.86)$; $\mathrm{P}=0.007]$. Compared to the control group, the neostigmine group had lower rates of abdominal distention $\left[\mathrm{RR}=0.39 ; 95 \% \mathrm{CI}:(0.18,0.87) ; \mathrm{P}=0.02 ; \mathrm{I}^{2}=76 \%\right]$ and overall adverse events $[\mathrm{RR}=0.49 ; 95 \% \mathrm{CI}$ : (0.29, 0.82); $\mathrm{P}=0.007]$. However, two groups had no difference in postoperative nausea and vomiting (PONV) $[\mathrm{RR}=0.50 ; 95 \% \mathrm{CI}:(0.21,1.23) ; \mathrm{P}=0.13]$, and respiratory complications $[\mathrm{RR}=0.96 ; 95 \% \mathrm{CI}:(0.20,4.53)$; $\mathrm{P}=0.96]$. Sensitivity and publication bias analyses showed that these results were robust and exhibited little publication bias.
\end{abstract}

Discussion: Small doses of neostigmine may promote the recovery of postoperative gastrointestinal function without obvious side effects.

Keywords: Neostigmine; gastrointestinal function; post-operation

Submitted Oct 19, 2021. Accepted for publication Dec 15, 2021.

doi: 10.21037/apm-21-3291

View this article at: https://dx.doi.org/10.21037/apm-21-3291

\section{Introduction}

Postoperative ileus (POI) is a common disease after gastrointestinal and other types of operations, such as orthopaedic, gynaecological, and urological surgeries, which leads to an increased incidence of several disease, hospitalization expenses, and 30-day readmission (1). In the past, it was generally believed that one of the normal compulsory physiological reactions of abdominal surgery is a certain degree of POI, and this reaction has no serious sequelae $(2,3)$. However, POI could be caused by the inflammatory response in intestinal operation, which leads to the long-term inhibition of intestinal synergistic activity. The prolongation of intestinal obstruction will lead to patient discomfort and prolonged hospital stay. Prolonged POI is the main reason for the extended recovery period, protracted hospital stay, and increased medical expenses. 
According to previous reports, the estimated incidence of POI in the United States in 2002 was approximately $17-$ $80 \%$, and the total hospital cost caused by POI was as high as US\$1.46 billion (4).

The underlying mechanism of POI is multifactorial and not yet completely understood. The main risk factors of POI include fluid overload, neurohormonal dysfunction, gastrointestinal stretch, and inflammation (5). Activation of the sympathetic nervous system, release of inflammatory mediators and immigration of leucocytes into the intestinal wall, stimulation of opioid receptors due to perioperative opioid usage, and edema of the intestinal wall due to fluid overload are considered the causes of postoperative gastrointestinal dysmotility (4). By introducing enhanced recovery after surgery (ERAS) protocols, laparoscopic procedures, and epidural anaesthesia, the incidence of POI may be reduced (6-8). However, it remains a problem in daily postoperative care. Therefore, prokinetic drugs, such as neostigmine, are widely administered in surgical wards. Neostigmine is a water-soluble, ionized compound that inhibits acetylcholinesterase (AChE). Its indication in FDA is to reverse the effect of non-depolarizing neuromuscular blockers after surgery. The drug is usually administered by intravenous injection, and the main route of excretion is the kidney. Neostigmine should be used with caution in patients with coronary heart disease, arrhythmia, recent acute coronary syndrome and myasthenia gravis (9). It was reported that neostigmine was used to treat POI in several disease types patients (10).

The previous studies had little analysis on neostigmine for postoperative recovery of gastrointestinal function, meanwhile there are several studies about the effect of neostigmine on POI; yet, there are few comprehensive reviews in this field. We conducted this meta-analysis to assess the safety and efficacy of neostigmine for the recovery of postoperative gastrointestinal function.

We present the following article in accordance with the PRISMA reporting checklist (available at https://dx.doi. org/10.21037/apm-21-3291).

\section{Methods}

\section{Literature search strategy}

A comprehensive literature search was conducted to retrieve eligible studies published between January 2000 and 2021 in the following electronic databases: PubMed, Web of Science, Cochrane Library and China National Knowledge
Internet (CNKI). The keywords used included neostigmine, gastrointestinal function, and postoperative ileus or POI.

We used the Boolean operators "and" and "OR" to expand the search scope by combining the set words and strings. A comprehensive search of trials without language or publication status restrictions was performed. We then performed data extraction; one of us ( $\mathrm{Li})$ performed all of the data extraction, and two of us (Liao and Ouyang) conducted independent verification.

\section{Study selection}

The inclusion criteria were specified according to the population, interventions, comparisons, outcomes, and setting/study design (PICOS) reporting structure, and were as follows: (I) language was restricted to English or Chinese publications; (II) patients received neostigmine; (III) studies focused on the gastrointestinal function of patients; (IV) study type is randomized control trials (RCTs); and (V) articles with sufficient data provided by means of indicators with standard deviation.

Studies were excluded according to the following criteria: (I) studies lacking available data; (II) non-Chinese or English articles; (III) duplicates, reviews, letters, case reports, comments, or editorials; (IV) studies involving simple descriptions without comparison; and (V) articles with an absence of key information.

\section{Data extraction and quality assessment}

Two reviewers independently screened the titles, abstracts, and full texts of the potentially eligible studies, and resolved disagreements through discussion. We used structured data tables to extract the required data elements from each trial, including baseline characteristics, sample size, and interventions used. The validity of eligible RCTs was assessed using the Cochrane risk of bias tool in Review Manager 5.2 (Cochrane Collaboration, 2020). Egger's tests and funnel plots were planned to evaluate the risk of bias across studies.

\section{Statistical analysis}

We assessed the efficacy and safety of neostigmine for the postoperative recovery of gastrointestinal function by pooling the standard mean difference (SMD) or risk ratios (RRs) using the DerSimonian-Laird random-effects model 
from RCTs and non-randomized studies, respectively.

Standardized differences were calculated based on the mean differences (control vs. neostigmine) of the several indicators (end of treatment) means and standard deviations. Heterogeneity was assessed by calculating the Cochrane $\mathrm{Q}$ statistics and $\mathrm{I}^{2}$ statistics. If there was no statistical heterogeneity among the included studies, the fixed effect model was used for meta-analysis; otherwise, the random effect model was applied. The Egger's test and a funnel plot were used to examine potential publication bias. Sensitivity analysis was further conducted to evaluate the robustness of the findings through exponential tilting. The Review Manager (Version 5.2, Cochrane Collaboration, 2011) was used to estimate the impact of the results in the selected report. To measure the consistency of the effect size, SMD and RR were used. $\mathrm{I}^{2}$ statistics was used to test the heterogeneity. If $\mathrm{I}^{2}>50 \%$, it meant that there was a certain degree of heterogeneity among the studies, and the random effect model would be used for analysis; if $\mathrm{I}^{2} \leq 50 \%$, it meant that there was no heterogeneity or less heterogeneity between the studies, and the fixed effect model would be used for analysis.

\section{Results}

\section{Search process}

A literature search in four databases identified 862 unique studies and 77 were retrieved for full-text assessment. After the removal of ineligible design, insufficient data files, and reviews, we conducted further screening. We screened the titles and abstracts of these articles and removed nonrelated articles. Finally, 17 publications remained for further screening.

A total of 17 studies met the inclusion/exclusion criteria and were included in the present meta-analysis (Figure 1).

\section{Characteristics of included studies}

The detailed characteristics of these 17 eligible studies were summarized in Table 1 (9-25). For each RCT, the following characteristics were collected: first author, publication year, number of patients in each group, interventions in this meta-analysis, gender and age distribution of participants, and any related results. These studies included a total of 1,608 patients who received surgeries. The included studies were published in the Chinese or English languages.

\section{Quality assessment results}

The risk-of-bias assessment for each of the included studies was summarized in Figure 2. There was a high risk of selection bias, performance bias, and detection bias in five different studies (Figure 2).

A summary of the risk-of-bias assessment for each study is shown in Figure 3. The Begg's tests showed that there was no publication bias in our study $(\mathrm{P}=0.45)$.

\section{Results of heterogeneity test}

\section{Primary outcomes}

\section{Heterogeneity analysis about first passage of flatus}

Thirteen studies including 589 patients in the neostigmine group and 572 patients in control group were involved in the heterogeneity analysis of the first passage of flatus (Figure 4). All 13 studies showed statistically significant differences of the first flatus passage between the neostigmine and control groups. The times of the first passage of flatus in the neostigmine group were shorter than those of the control group [SMD $=-3.00 ; 95 \%$ confidence interval (CI): $(-4.03,-1.97)$; overall $\mathrm{P}<0.001$; $\mathrm{P}$ for heterogeneity $<0.001 ; \mathrm{I}^{2}=98 \%$ using random effect model].

Heterogeneity analysis regarding first defecation between the neostigmine and control groups

Six articles were included in this analysis. The heterogeneity test results showed that the random effect model was needed to analyze the data ( $\mathrm{P}$ of heterogeneity $<0.001 ; \mathrm{I}^{2}=98 \%$; $\mathrm{P}$ of overall effect $<0.001)$. The overall effect of first defecation was significant and the SMD was -3.75 with $95 \%$ CI: $(-5.25$, -2.24), showing that the neostigmine group had earlier first defecation than control group (Figure 5).

Heterogeneity analysis regarding the time of bowel sound recovery in the neostigmine and control groups

As shown in Figure 6, 10 included studies were involved in the analysis of bowel sound recovery time between the neostigmine and control groups. The bowel sound recovery time of the neostigmine group was less than that of the control group [SMD $=-3.42 ; 95 \%$ CI: $(-4.49,-2.36)$; $\left.\mathrm{P}<0.001 ; \mathrm{I}^{2}=97 \%\right]$.

\section{Secondary outcomes Heterogeneity analysis regarding the gastrointestinal function recovery between the neostigmine and control groups}

Five articles were included in the analysis of gastrointestinal 


\section{Identification of studies via databases and registers}
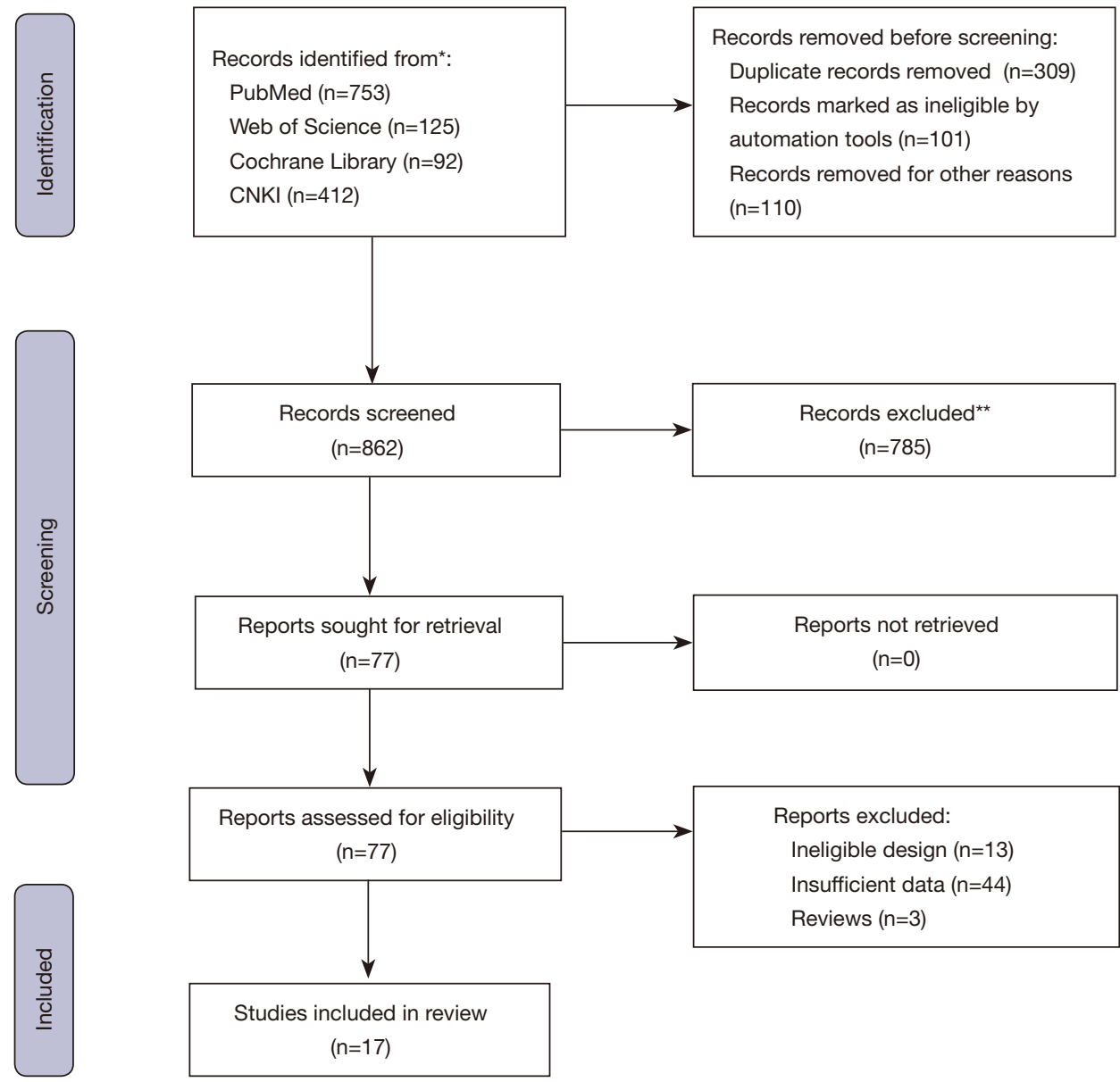

Figure 1 Literature selection flow chart. CNKI, China National Knowledge Internet. *, consider, if feasible to do so, reporting the number of records identified from each database or register searched (rather than the total number across all databases/registers). **, if automation tools were used, indicate how many records were excluded by a human and how many were excluded by automation tools. From: Page MJ, McKenzie JE, Bossuyt PM, et al. The PRISMA 2020 statement: an updated guideline for reporting systematic reviews. BMJ 2021;372:n71. For more information, visit: http://www.prisma-statement.org/.

function recovery between the neostigmine and control groups. The heterogeneity test results showed that random effect model was needed to analyze the data $(\mathrm{P}$ of heterogeneity $<0.001 ; \mathrm{I}^{2}=90 \%$; P of over effect $\left.=0.007\right)$. The overall effect of gastrointestinal function recovery was significant; the overall RR was 1.84 with $95 \% \mathrm{CI}$ : $(1.19,2.86)$. The gastrointestinal function recovery of the neostigmine group was superior to that of the control group (Figure 7).

\section{Heterogeneity analysis regarding the adverse events between the neostigmine and control groups}

The adverse events (e.g., nausea, vomiting, abdominal distention, respiratory complications) in the two arms were compared by overall analysis and further subgroup analysis (Figure 8). In the overall analysis, the rate of adverse events was markedly different between the neostigmine and control groups $[\mathrm{RR}=0.49 ; 95 \% \mathrm{CI}$ : $(0.29,0.82) ; \mathrm{P}=0.007$; $\left.\mathrm{I}^{2}=75 \%\right]$, and the control group had higher rates of adverse 
Table 1 Baseline data of included studies

\begin{tabular}{|c|c|c|c|c|c|c|c|}
\hline Study & Year & Groups & $\begin{array}{c}\text { Dosage of } \\
\text { neostigmine }\end{array}$ & Treatment & Sex (male/female) & $\begin{array}{l}\text { Age (years), } \\
\text { mean } \pm S D\end{array}$ & $\mathrm{~N}$ \\
\hline \multirow[t]{2}{*}{ Caliskan } & 2008 & Neostigmine & $1 \mu \mathrm{g} / \mathrm{kg}$ & Epidural catheter & $17 / 1$ & $57 \pm 8$ & 18 \\
\hline & & Control & - & Normal saline & $16 / 0$ & $63 \pm 7$ & 16 \\
\hline Chen & 2012 & Neostigmine & $1 \mathrm{mg}$ & Acupoint injection & $19 / 16$ & $47.3 \pm 12$ & 35 \\
\hline \multirow[t]{2}{*}{ Chen } & 2020 & Neostigmine & $1-2 \mathrm{mg}$ & $\begin{array}{l}\text { Acupoint injection + } \\
\text { conventional therapy }\end{array}$ & $36 / 16$ & $54.4 \pm 11.4$ & 52 \\
\hline & & Control & - & Conventional therapy & $37 / 18$ & $55.3 \pm 9.4$ & 55 \\
\hline Feng & 2014 & Neostigmine & $1 \mathrm{mg}$ & $\begin{array}{l}\text { Acupoint injection }+ \\
\text { conventional therapy }\end{array}$ & $21 / 14$ & $45.2 \pm 7.2$ & 35 \\
\hline Gao & & Control & - & Conventional therapy & $11 / 9$ & $45 \pm 23$ & 20 \\
\hline \multirow[t]{2}{*}{ Geng } & 2019 & Neostigmine & $1 \mathrm{mg}$ & Acupoint injection & $25 / 16$ & $42.2 \pm 13.3$ & 41 \\
\hline & & Control & - & Conventional therapy & 22/19 & $41.2 \pm 13.7$ & 41 \\
\hline \multirow[t]{2}{*}{ Jiang } & 2001 & Neostigmine & $1 \mathrm{mg}$ & Epidural catheter & $0 / 20$ & - & 20 \\
\hline & & Control & - & Normal saline & $0 / 20$ & - & 20 \\
\hline \multirow[t]{2}{*}{ Qiu } & 2015 & Neostigmine & $2 \mathrm{mg}$ & Acupoint injection & $18 / 22$ & $43.2 \pm 5.8$ & 40 \\
\hline & & Control & - & Conventional therapy & $19 / 21$ & $43.3 \pm 5$ & 40 \\
\hline Shao & 2014 & Neostigmine & $1 \mathrm{mg}$ & Acupoint injection & $24 / 8$ & $67.3 \pm 10.3$ & 32 \\
\hline Wu & & Control & - & Normal saline & $16 / 14$ & $57 \pm 18$ & 30 \\
\hline \multirow[t]{2}{*}{$X i$} & 2015 & Neostigmine & $2 \mathrm{mg}$ & Acupoint injection & $16 / 14$ & $54 \pm 14$ & 30 \\
\hline & & Control & - & Conventional therapy & $15 / 15$ & $54.2 \pm 13.1$ & 30 \\
\hline \multirow[t]{2}{*}{ You } & 2018 & Neostigmine & $1 \mathrm{mg}$ & Acupoint injection & $50 / 17$ & - & 67 \\
\hline & & Control & - & Conventional therapy & $37 / 16$ & - & 53 \\
\hline \multirow[t]{2}{*}{ Zeng } & 2015 & Neostigmine & $1 \mathrm{mg}$ & Acupoint injection & $45 / 30$ & $53.5 \pm 6.3$ & 75 \\
\hline & & Control & - & Conventional therapy & - & - & 75 \\
\hline \multirow[t]{2}{*}{ Zhang } & 2012 & Neostigmine & $1 \mathrm{mg}$ & Acupoint injection & $24 / 22$ & 63 & 46 \\
\hline & & Control & - & Conventional therapy & $22 / 23$ & 61 & 45 \\
\hline \multirow[t]{2}{*}{ Zhang } & 2021 & Neostigmine & $1 \mathrm{mg}$ & Intramuscular injection & $0 / 120$ & $28.7 \pm 2.2$ & 120 \\
\hline & & Control & - & Conventional therapy & $0 / 120$ & $29.2 \pm 2.1$ & 120 \\
\hline \multirow[t]{2}{*}{ Zhu } & 2006 & Neostigmine & $1 \mathrm{mg}$ & Analgesic pump & $0 / 126$ & - & 126 \\
\hline & & Control & - & Analgesic pump & $0 / 114$ & - & 114 \\
\hline
\end{tabular}




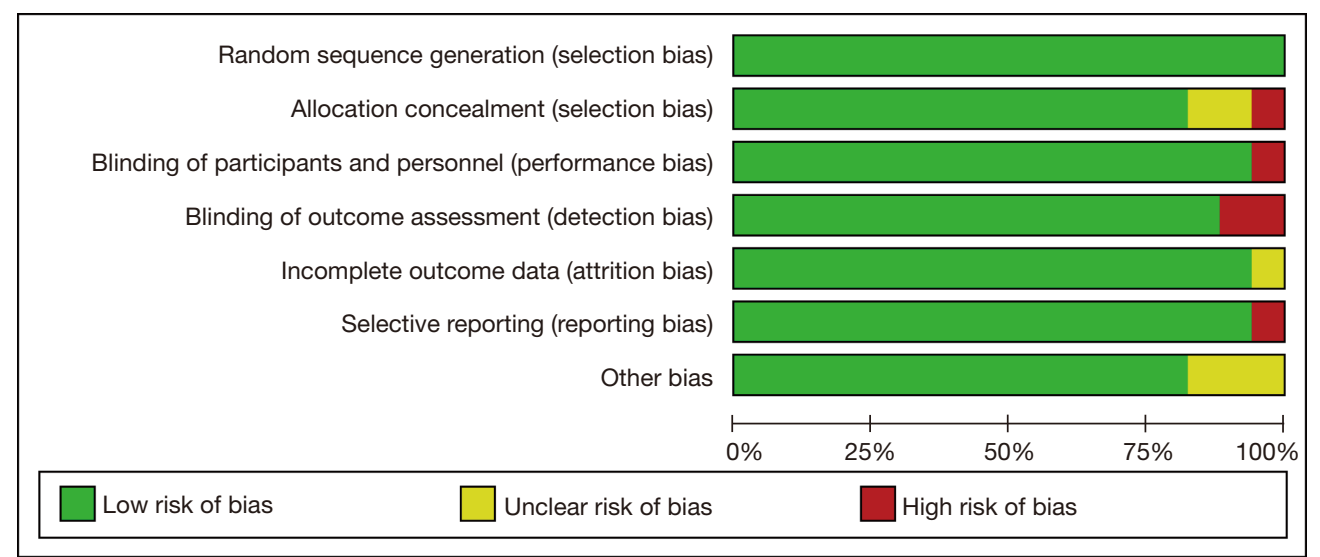

Figure 2 Quality assessment of the studies in this meta-analysis. High, low, and unclear risk of bias were marked in red, green, and yellow, respectively.

events rate than the neostigmine group.

In the subgroup analysis, there was no significant difference in the rates of nausea, vomiting, and respiratory complications between the neostigmine and control groups [nausea and vomiting: $\mathrm{RR}=0.50$ with $95 \% \mathrm{CI}$ : (0.21, 1.23), $\mathrm{P}=0.13$ and $\mathrm{I}^{2}=82 \%$; respiratory complications: $\mathrm{RR}$ $=0.96$ with $95 \%$ CI: $(0.20,4.53), \mathrm{P}=0.96$ and $\left.\mathrm{I}^{2}=0 \%\right]$. The abdominal distention rate of the neostigmine group was lower than that of the control group $[\mathrm{RR}=0.39 ; 95 \% \mathrm{CI}$ : $\left.(0.18,0.87) ; \mathrm{P}=0.02 ; \mathrm{I}^{2}=76 \%\right]$.

\section{Results of sensitivity analysis and publication bias}

The meta-analysis results showed that the heterogeneity of flatus passage was high $\left(\mathrm{I}^{2}=98 \%\right)$. As shown in Figure 9, the heterogeneity of the flatus passage might be attributed to the differences between different studies. When You's research in 2018 (21) was removed, the $\mathrm{I}^{2}$ value changed from $98 \%$ to $96 \%$. This showed that the results of this paper were stable.

Funnel plots of the first passage of flatus in the neostigmine and control groups were constructed. Thirteen studies were included in the plot. The results showed that the funnel plot had good symmetry and little publication bias (Figure 10). The result of Begg's test suggested that no significant evidence of potential publication bias existed $(\mathrm{z}=1.83 ; \mathrm{P}=0.24)$. The result of Egger's test also suggested that no significant evidence of potential publication bias existed $(\mathrm{t}=2.54 ; \mathrm{P}=0.35)$.

\section{Discussion}

Postoperative intestinal obstruction refers to the obstruction and intolerance of oral intake caused by factors that interfere with the normal coordination of the gastrointestinal tract to promote sporting activities. Neostigmine is often prescribed for patients with symptoms of POI to promote gastrointestinal function recovery after abdominal surgery. In this study, we reviewed the efficacy and safety outcomes of neostigmine in patients with POI.

Thirteen studies reported the time to first passage of flatus, and all 13 studies showed that patients prescribed with Neostigmine had a shorter time to first passage of flatus. Six studies reported the first defecation postoperatively, and the analysis of 10 involved studies showed that bowel sound recovery time in the neostigmine group was lower than that of the control group. In the enteric nervous system, AChE inhibitors can prevent the degradation of acetylcholine (ACh) and increase the utilization of $\mathrm{ACh}$, thereby increasing gastrointestinal movement. It was reported that neostigmine has successfully treated POI, intestinal pseudo-obstruction, refractory constipation, spinal injury-induced constipation, and opioid-induced constipation in cancer patients (26-29). In a randomized trial, 21 patients with acute colonic pseudo-obstruction were assigned to treatment with either neostigmine or a placebo. Prompt decompression was observed in 11 patients who received neostigmine compared with none who received the placebo (30). Neostigmine has 


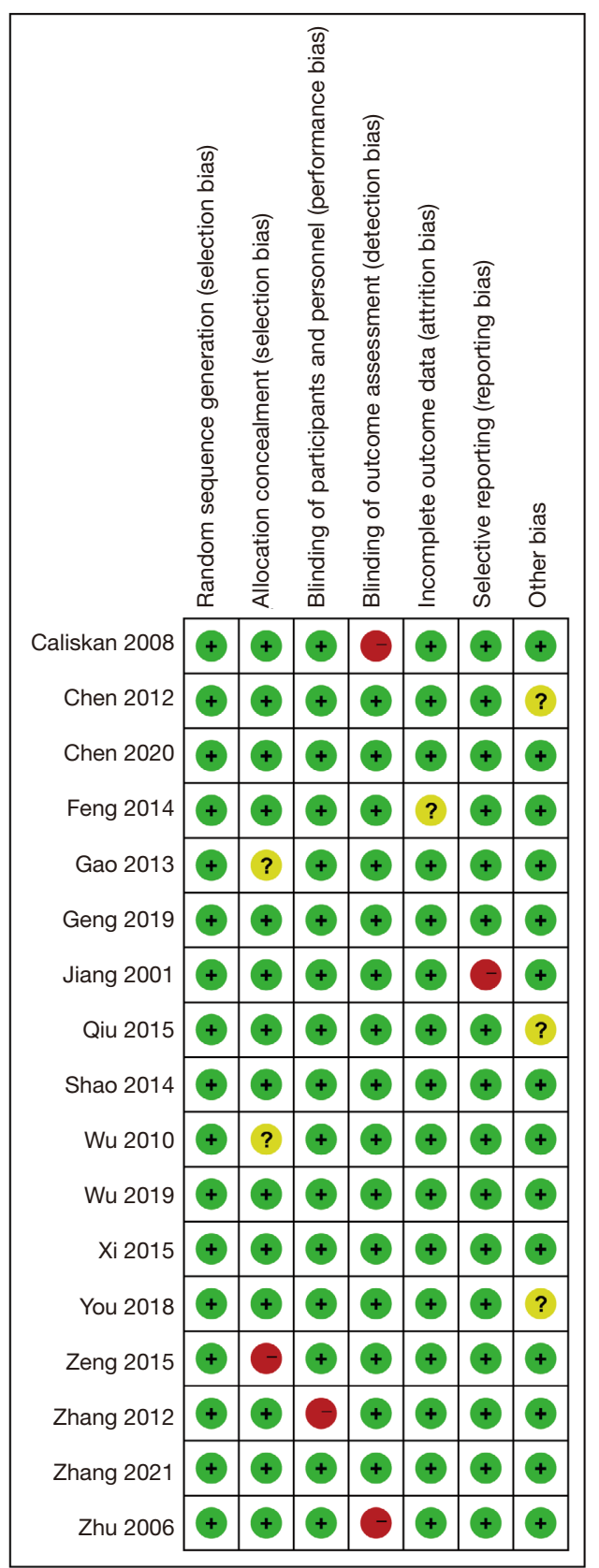

Figure 3 Risk of bias summary of the included studies.

a strong excitatory effect on gastrointestinal and bladder smooth muscle, and can promote the peristalsis of stomach, intestine and colon.

In the secondary outcomes, we analyzed the adverse events associated with neostigmine. The analysis of all 17 studies showed no difference in the occurrence of postoperative nausea and vomiting (PONV) and respiratory complications between the neostigmine and control groups, indicating that neostigmine can be well tolerated and safely prescribed. A previous meta-analysis on neostigmine as a neuromuscular blocking antagonist after anesthesia also found no significant increase in the risk of vomiting (31). Parthasarathy et al. (32) reported that neostigmine could also improve symptoms of irritable bowel syndrome, help 


\begin{tabular}{|c|c|c|c|c|c|c|c|c|c|c|}
\hline \multirow{2}{*}{ Study or Subgroup } & \multicolumn{3}{|c|}{ Neostigmine } & \multicolumn{3}{|c|}{ Control } & \multicolumn{2}{|r|}{ Std. Mean Difference } & \multirow{2}{*}{\multicolumn{2}{|c|}{$\begin{array}{l}\text { Std. Mean Difference } \\
\text { IV, Random, } 95 \% \mathrm{Cl}\end{array}$}} \\
\hline & Mean & SD & & Mean & SD & otal & Welght & IV. Random, $95 \%$ Cl & & \\
\hline Caliskan 2008 & 21 & 15 & 18 & 36 & 19 & 16 & $8.1 \%$ & $-0.86[-1.57,-0.15]$ & & \\
\hline Chen 2012 & 3.1 & 0.5 & 35 & 7.3 & 2.8 & 35 & $8.2 \%$ & $-2.07[-2.65,-1.48]$ & I & \\
\hline Feng 2014 & 38.7 & 3.4 & 35 & 53.4 & 4.5 & 35 & $8.0 \%$ & $-3.65[-4.42,-2.87]$ & $=$ & \\
\hline Gao 2013 & 29 & 4.5 & 20 & 61 & 7 & 20 & $7.3 \%$ & $-5.33[-6.71,-3.95]$ & $=$ & \\
\hline Geng 2019 & 31.6 & 6.3 & 41 & 33.8 & 7.5 & 41 & $8.3 \%$ & $-0.31[-0.75,0.12]$ & & \\
\hline Qiu 2015 & 36.8 & 10.3 & 40 & 54.4 & 11.1 & 40 & $8.2 \%$ & $-1.63[-2.14,-1.12]$ & . & \\
\hline Shao 2014 & 65.2 & 9.5 & 32 & 44.8 & 7 & 32 & $8.1 \%$ & $2.42[1.76,3.07]$ & & - \\
\hline Wu 2019 & 56.2 & 2.7 & 30 & 68.3 & 3.1 & 30 & $7.9 \%$ & $-4.11[-5.02,-3.19]$ & $=$ & \\
\hline Xi 2015 & 23.9 & 5.4 & 30 & 42.9 & 5.7 & 30 & $8.0 \%$ & $-3.38[-4.18,-2.57]$ & $=$ & \\
\hline You 2018 & 2.3 & 0.6 & 67 & 44.2 & 1.7 & 53 & $3.3 \%$ & $-34.28[-38.71,-29.86]$ & $\vdash$ & \\
\hline Zeng 2015 & 31.2 & 9.5 & 75 & 51.3 & 10.5 & 75 & $8.3 \%$ & $-2.00[-2.39,-1.60]$ & 1 & \\
\hline Zhang 2012 & 36.3 & 14.3 & 46 & 57.5 & 17.3 & 45 & $8.2 \%$ & $-1.33[-1.78,-0.87]$ & $=$ & \\
\hline Zhang 2021 & 25 & 3 & 120 & 30.2 & 4 & 120 & $8.3 \%$ & $-1.47[-1.75,-1.18]$ & - & \\
\hline Total $(95 \% \mathrm{Cl})$ & & & 589 & & & 572 & $100.0 \%$ & $-3.00[-4.03,-1.97]$ & 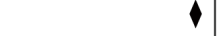 & \\
\hline $\begin{array}{l}\text { Heterogeneity: } \mathrm{Tau}^{2}= \\
\text { Test for overall effect: }\end{array}$ & $\begin{array}{l}3.31 ; \mathrm{Chi} \\
=5.70\end{array}$ & $\begin{array}{l}\mathrm{i}^{2}=50 \\
(\mathrm{P}<0\end{array}$ & $\begin{array}{l}2.08, \mathrm{df} \\
.00001)\end{array}$ & $f=12$ & $P<0.0$ & 001); & $2^{2}=98 \%$ & & $\begin{array}{cc}-20 & -10 \\
\text { Neostigmine }\end{array}$ & $\begin{array}{cc}10 & 20 \\
\text { Control } & \end{array}$ \\
\hline
\end{tabular}

Figure 4 Forest plot: comparison of the first passage of flatus between the neostigmine and control groups.

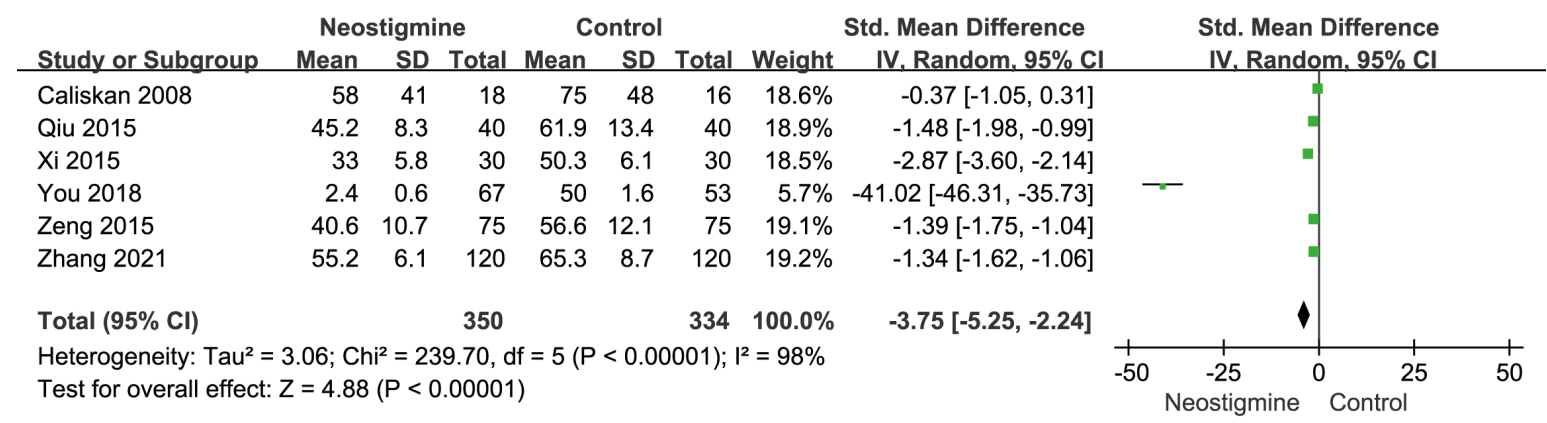

Figure 5 Forest plot: comparison of the first defecation between the neostigmine and control groups.

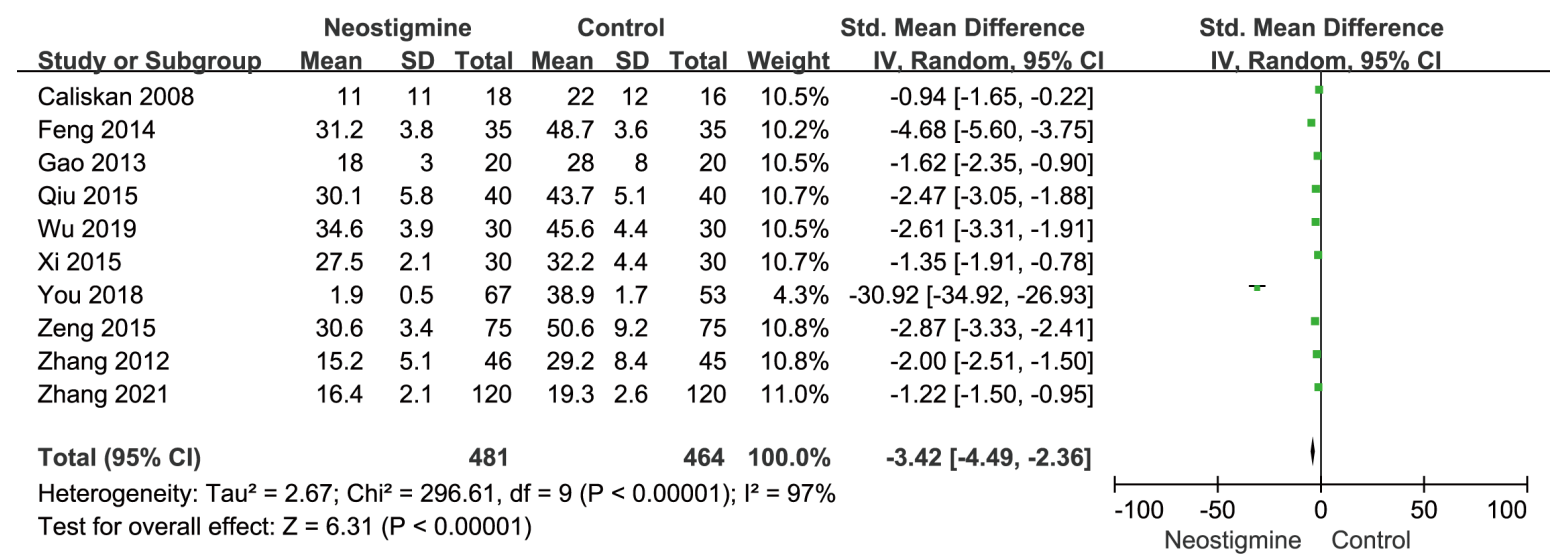

Figure 6 Forest plot: comparison of the time of bowel sound recovery between the neostigmine and control groups. 


\begin{tabular}{|c|c|c|c|c|c|c|c|c|c|c|}
\hline Studv or Subaroun & Neostigr & ine & Contro & & & Risk Ratio & \multirow{2}{*}{\multicolumn{4}{|c|}{$\begin{array}{c}\text { Risk Ratio } \\
\text { M-H, Random, } 95 \% \text { CI }\end{array}$}} \\
\hline Chen 2020 & 51 & 52 & 38 & 55 & $21, \%$ & 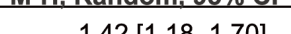 & & & & \\
\hline Qiu 2015 & 35 & $\begin{array}{l}52 \\
40\end{array}$ & $\begin{array}{l}38 \\
24\end{array}$ & $\begin{array}{l}55 \\
40\end{array}$ & $\begin{array}{l}24.4 \% \\
23.1 \%\end{array}$ & $\begin{array}{l}1.42[1.18,1 . / 0] \\
1.46[110.193]\end{array}$ & & & - & \\
\hline Wu 2010 & 28 & 30 & 19 & 30 & $22.9 \%$ & $1.47[1.10,1.97]$ & & & - & \\
\hline Wu 2019 & 28 & 30 & 17 & 30 & $22.3 \%$ & $1.65[1.19,2.28]$ & & & - & \\
\hline You 2018 & 63 & 67 & 2 & 53 & $7.4 \%$ & $24.92[6.39,97.17]$ & & & & \\
\hline Total (95\% Cl) & & 219 & & 208 & $100.0 \%$ & $1.84[1.19,2.86]$ & & & & \\
\hline Total events & 205 & & 100 & & & & & & & \\
\hline $\begin{array}{l}\text { Heterogeneity: } \mathrm{Tau}^{2}= \\
\text { Test for overall effect: }\end{array}$ & $\begin{array}{l}.20 ; \mathrm{Chi}^{2} \\
=2.72(\mathrm{P}\end{array}$ & $\begin{array}{r}38.13, \\
=0.007\end{array}$ & $d f=4(P$ & $<0.00$ & $001) ; I^{2}=$ & & $\begin{array}{l}0.01 \\
\mathrm{Ne}\end{array}$ & $\begin{array}{ll}0.1 & 1 \\
\text { eostigmine }\end{array}$ & 1 Control & 100 \\
\hline
\end{tabular}

Figure 7 Forest plot: comparison of the first passage of gastrointestinal function recovery between the neostigmine and control groups.

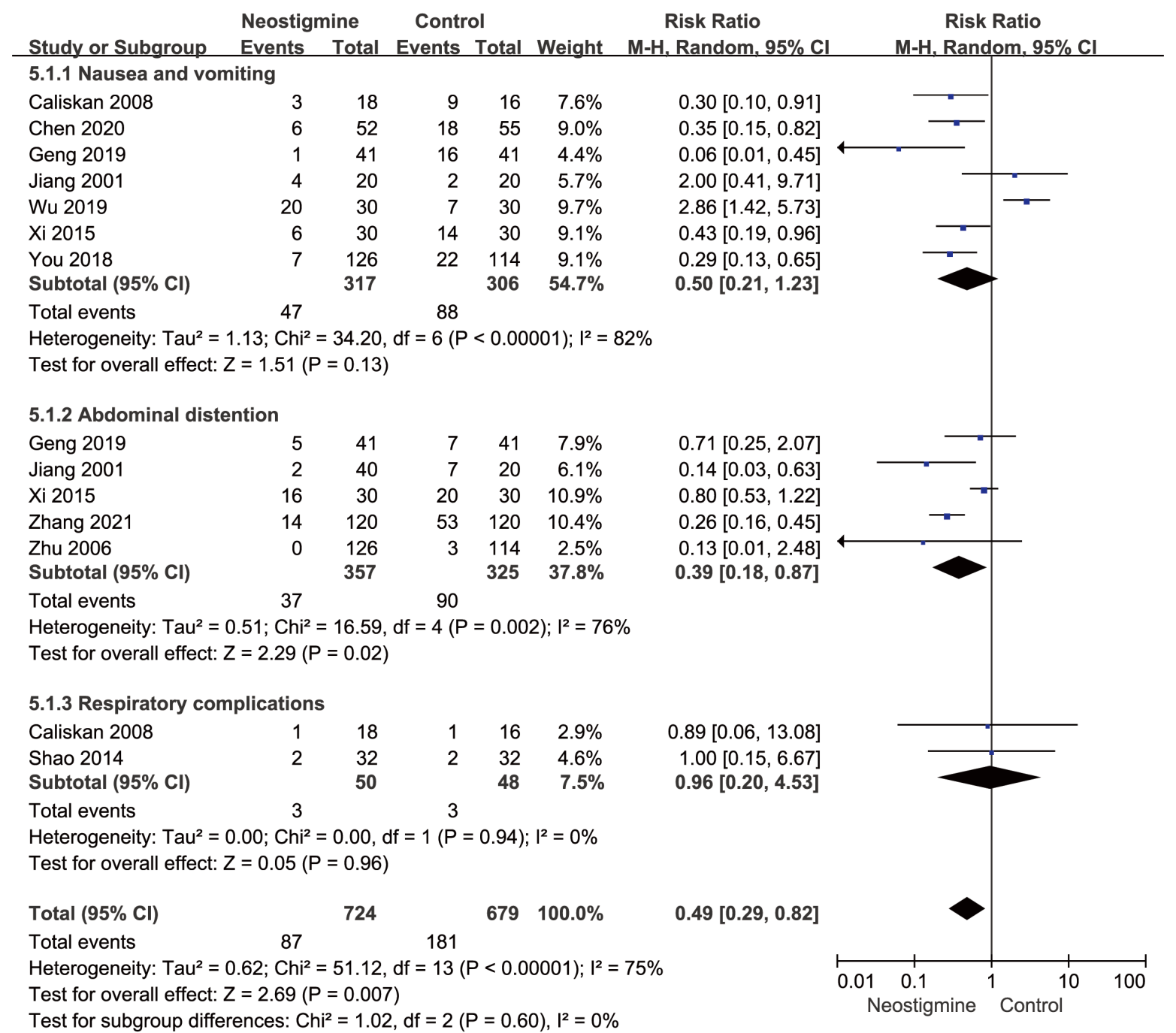

Figure 8 Forest plot: comparison of the adverse events between the neostigmine and control groups. 


\begin{tabular}{|c|c|c|c|c|c|c|c|c|c|}
\hline \multirow[b]{2}{*}{ Study or Subgroup } & \multicolumn{3}{|c|}{ Neostigmine } & \multicolumn{2}{|c|}{ Control } & \multirow[b]{2}{*}{ Total } & \multirow[b]{2}{*}{ Weight } & \multirow{2}{*}{$\begin{array}{l}\text { Std. Mean Difference } \\
\text { IV. Random, } 95 \% \mathrm{Cl}\end{array}$} & \multirow{2}{*}{$\begin{array}{l}\text { Std. Mean Difference } \\
\text { IV. Random, } 95 \% \mathrm{CI}\end{array}$} \\
\hline & Mean & SD & Total & Mean & SD & & & & \\
\hline Caliskan 2008 & 21 & 15 & 18 & 36 & 19 & 16 & $8.2 \%$ & $-0.86[-1.57,-0.15]$ & 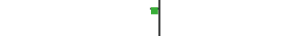 \\
\hline Chen 2012 & 3.1 & 0.5 & 35 & 7.3 & 2.8 & 35 & $8.4 \%$ & $-2.07[-2.65,-1.48]$ & - \\
\hline Feng 2014 & 38.7 & 3.4 & 35 & 53.4 & 4.5 & 35 & $8.1 \%$ & $-3.65[-4.42,-2.87]$ & $=$ \\
\hline Gao 2013 & 40 & 5 & 20 & 61 & 7 & 20 & $7.7 \%$ & $-3.38[-4.38,-2.39]$ & $=$ \\
\hline Geng 2019 & 31.6 & 6.3 & 41 & 33.8 & 7.5 & 41 & $8.6 \%$ & $-0.31[-0.75,0.12]$ & \\
\hline Qiu 2015 & 36.8 & 10.3 & 40 & 54.4 & 11.1 & 40 & $8.5 \%$ & $-1.63[-2.14,-1.12]$ & - \\
\hline Shao 2014 & 65.2 & 9.5 & 32 & 44.8 & 7 & 32 & $8.3 \%$ & $2.42[1.76,3.07]$ & $=$ \\
\hline Wu 2019 & 56.2 & 2.7 & 30 & 68.3 & 3.1 & 30 & $7.9 \%$ & $-4.11[-5.02,-3.19]$ & $=$ \\
\hline Xi 2015 & 23.9 & 5.4 & 30 & 42.9 & 5.7 & 30 & $8.1 \%$ & $-3.38[-4.18,-2.57]$ & $=$ \\
\hline Zeng 2015 & 31.2 & 9.5 & 75 & 51.3 & 10.5 & 75 & $8.7 \%$ & $-2.00[-2.39,-1.60]$ & - \\
\hline Zhang 2012 & 36.3 & 14.3 & 46 & 57.5 & 17.3 & 45 & $8.6 \%$ & $-1.33[-1.78,-0.87]$ & $"$ \\
\hline Zhang 2021 & 25 & 3 & 120 & 30.2 & 4 & 120 & $8.8 \%$ & $-1.47[-1.75,-1.18]$ & - \\
\hline Total $(95 \% \mathrm{Cl})$ & & & 522 & & & 519 & $100.0 \%$ & $-1.78[-2.55,-1.01]$ & 1 \\
\hline \multicolumn{9}{|c|}{ Heterogeneity: $\mathrm{Tau}^{2}=1.76 ; \mathrm{Chi}^{2}=275.18, \mathrm{df}=11(\mathrm{P}<0.00001) ; \mathrm{I}^{2}=96 \%$} & $\begin{array}{cccc}-20 & -10 & 0 & 10 \\
\text { Neostigmine } & \text { Control }\end{array}$ \\
\hline
\end{tabular}

Figure 9 Sensitivity analysis forest plots of the first passage of flatus between the neostigmine and control groups.

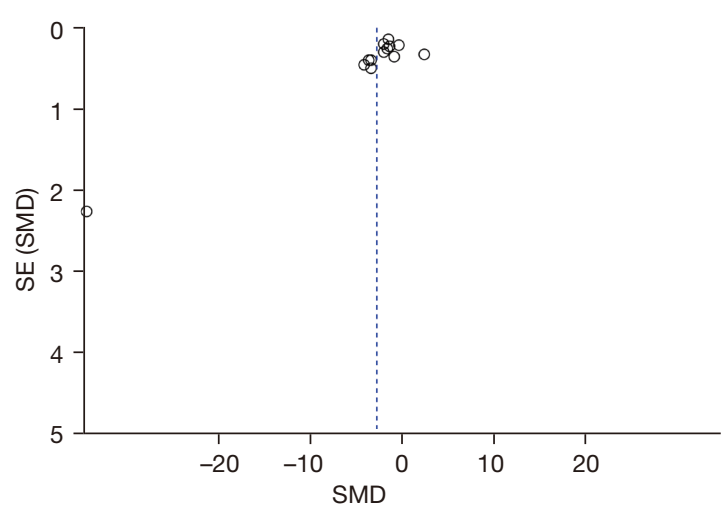

Figure 10 Funnel plot for publication bias in the first passage of flatus.

intestinal gas discharge, and reduce abdominal symptoms and abdominal distension, which is consistent with our results.

Although most included trials are of small, the funnel plot results showed good symmetry and little publication bias. Also, the Begg's test results also suggested that no significant evidence of potential publication bias existed.

In conclusion, prokinetic agents to decrease POI are commonly used in post-surgical management, and neostigmine is effective and safe for accelerating gastrointestinal function recovery after surgeries, acting to prevent and alleviate symptoms of POI without additional side effects. Our findings should be understood with caution due to the small sample sizes of the included studies. A large number of trials involving a large study population and high methodological quality are required to further confirm the beneficial effects of neostigmine.

\section{Acknowledgments}

Funding: None.

\section{Footnote}

Reporting Checklist: The authors have completed the PRISMA reporting checklist. Available at https://dx.doi. org/10.21037/apm-21-3291

Conflicts of Interest: All authors have completed the ICMJE uniform disclosure form (available at https://dx.doi. org/10.21037/apm-21-3291). The authors have no conflicts of interest to declare.

Ethical Statement: The authors are accountable for all aspects of the work in ensuring that questions related to the accuracy or integrity of any part of the work are appropriately investigated and resolved.

Open Access Statement: This is an Open Access article distributed in accordance with the Creative Commons Attribution-NonCommercial-NoDerivs 4.0 International License (CC BY-NC-ND 4.0), which permits the noncommercial replication and distribution of the article with the strict proviso that no changes or edits are made and the original work is properly cited (including links to both the formal publication through the relevant DOI and the 
license). See: https://creativecommons.org/licenses/by-nc$\mathrm{nd} / 4.0 /$.

\section{References}

1. Bragg D, El-Sharkawy AM, Psaltis E, et al. Postoperative ileus: recent developments in pathophysiology and management. Clin Nutr 2015;34:367-76.

2. Miedema BW, Johnson JO. Methods for decreasing postoperative gut dysmotility. Lancet Oncol 2003;4:365-72.

3. Wilson JP. Postoperative motility of the large intestine in man. Gut 1975;16:689-92.

4. Traut U, Brügger L, Kunz R, et al. Systemic prokinetic pharmacologic treatment for postoperative adynamic ileus following abdominal surgery in adults. Cochrane Database Syst Rev 2008;(1):CD004930.

5. Bugaev N, Bhattacharya B, Chiu WC, et al. Promotility agents for the treatment of ileus in adult surgical patients: a practice management guideline from the Eastern Association for the Surgery of Trauma. J Trauma Acute Care Surg 2019;87:922-34.

6. Guay J, Nishimori M, Kopp S. Epidural local anaesthetics versus opioid-based analgesic regimens for postoperative gastrointestinal paralysis, vomiting and pain after abdominal surgery. Cochrane Database Syst Rev 2016;7:CD001893.

7. Handunnetti SM, Gilladoga AD, van Schravendijk MR, et al. Purification and in vitro selection of rosette-positive $(\mathrm{R}+)$ and rosette-negative (R-) phenotypes of knob-positive Plasmodium falciparum parasites. Am J Trop Med Hyg 1992;46:371-81.

8. Schwenk W, Haase O, Neudecker J, et al. Short term benefits for laparoscopic colorectal resection. Cochrane Database Syst Rev 2005;(3):CD003145.

9. Caliskan E, Turkoz A, Sener M, et al. A prospective randomized double-blind study to determine the effect of thoracic epidural neostigmine on postoperative ileus after abdominal aortic surgery. Anesth Analg 2008;106:959-64, table of contents.

10. Chen GQ. Observation on the effect of Zusanli acupoint injection of two drugs on the recovery of gastrointestinal function after abdominal surgery. Journal of Aerospace Medicine 2012;23:976-7.

11. Chen H, Jiang XM, Xiong HR, et al. Effect of abdominal massage combined with neostigmine Zusanli acupoint injection on the recovery of gastrointestinal function in patients after cardiac surgery. International Medicine and Health Guidance News 2020;26:1916-8.

12. Feng XD, Xu YY. Effect of neostigmine Zusanli injection on 70 cases of gastrointestinal dysfunction after abdominal surgery. Chinese and Foreign Medical Research 2014;12:33-4.

13. Gao Q, Liu GH, Zhou LH, et al. Effect of neostigmine joint medical postoperative paste after gastrointestinal surgery. Modern Hospital 2013;13:73-4.

14. Geng X. Clinical observation of neostigmine injection at Zusanli point on the recovery of gastrointestinal function after LA. Qinghai Medical Journal 2019;49:18-20.

15. Jiang CD. Effect of epidural neostigmine on postoperative analgesia and gastrointestinal function after cesarean section. Acta Academiae Medcinac Nantong 2001;21:84-5.

16. Qiu WQ, Jiang JY. Effect of acupoint injection of neostigmine on gastrointestinal function after cholecystectomy. Journal of Acupuncture and Tuina Science 2015;13:368-72.

17. Shao Z, Guo W, Li L, et al. Influence of acupoint injection with neostigmine at $\mathrm{ZuSanLi}$ on the recovery of gastrointestinal function of senile patients after the surgery of esophageal cancer. Western Journal of Traditional Chinese Medicine 2014;27:114-5.

18. Wu HH, Yu ZY, Liang WL. Observation of neostigmine injection at Zusanli point in the treatment of abdominal distension after gastrointestinal surgery. International Medicine and Health Guidance News 2010;16:2151-2.

19. Wu YC, Hou JM. Clinical study of traditional Chinese medicine acupoint injection on gastrointestinal function recovery after gastrointestinal malignant tumor operation. Journal of Changchun University of Traditional Chinese Medicine 2019;35:85-7.

20. Xi Y, Niu SX, Mu LT, et al. Clinical study of different ways to promote the recovery of gastrointestinal function in patients with gastric cancer. The Journal of Practical Medicine 2015;31:1659-61.

21. You X, Wang Y, Wu J, et al. Zusanli (ST36) acupoint injection with neostigmine for paralytic postoperative ileus following radical gastrectomy for gastric cancer: a randomized clinical trial. J Cancer 2018;9:2266-74.

22. Zeng T, Li WX, Tian SJ. Influence of Zusanli acupoint injection of neostigmine on gastrointestinal function in patients after gastrointestinal surgery. World Chinese Journal of Digestology 2015;23:3955-9.

23. Zhang ML, Lv LY, Liu HS. Effect of neostigmine acupoint injection on postoperative abdominal distension. Chinese 
Journal of Practical Medicine 2012;39:94-5.

24. Zhang M, Liang TY, Qiang JY. Application of neostigmine methylsulfate injection in gastrointestinal function recovery after cesarean section. Chinese Journal of Woman and Child Health Research 2021;32:391-4.

25. Zhu BJ. Effect of persistent epidural neostigmine on bowel function after cesarean section. Journal of Medical Forum 2006;27:6-7.

26. Jarvie EM, Cellek S, Sanger GJ. Potentiation by cholinesterase inhibitors of cholinergic activity in rat isolated stomach and colon. Pharmacol Res 2008;58:297-301.

27. Ponec RJ, Saunders MD, Kimmey MB. Neostigmine for the treatment of acute colonic pseudo-obstruction. N Engl J Med 1999;341:137-41.

28. Saunders MD, Kimmey MB. Systematic review: acute colonic pseudo-obstruction. Aliment Pharmacol Ther
2005;22:917-25.

29. Kreis ME, Kasparek M, Zittel TT, et al. Neostigmine increases postoperative colonic motility in patients undergoing colorectal surgery. Surgery 2001;130:449-56.

30. Abeyta BJ, Albrecht RM, Schermer CR. Retrospective study of neostigmine for the treatment of acute colonic pseudoobstruction. Am Surg 2001;67:265-8; discussion 268-9.

31. Law NM, Bharucha AE, Undale AS, et al. Cholinergic stimulation enhances colonic motor activity, transit, and sensation in humans. Am J Physiol Gastrointest Liver Physiol 2001;281:G1228-37.

32. Parthasarathy G, Ravi K, Camilleri M, et al. Effect of neostigmine on gastroduodenal motility in patients with suspected gastrointestinal motility disorders. Neurogastroenterol Motil 2015;27:1736-46.

(English Language Editor: A. Kassem)
Cite this article as: Liao Y, Li Y, Ouyang W. Effects and safety of neostigmine for postoperative recovery of gastrointestinal function: a systematic review and meta-analysis. Ann Palliat Med 2021;10(12):12507-12518. doi: 10.21037/apm-21-3291 